\title{
Social Capital and the Human Psyche: Why Is Social Life "Capital"?*
}

\author{
JoAnne Savage \\ American University \\ Satoshi Kanazawa \\ University of Canterbury, New Zealand
}

\begin{abstract}
In this article, we propose a revised definition of social capital, premised on the principles of evolutionary psychology. We define social capital as any feature of a social relationship that, directly or indirectly, confers reproductive benefits to a participant in that relationship. This definition grounds the construct of social capital in human nature by providing a basis for inferring the underlying motivations that humans may have in common, rather than leaving the matter of what humans use capital for unspoken. Discussions and empirical reviews are presented on the innateness of human sociability, sex differences in sociability, and psychological mechanisms that mediate sociability.
\end{abstract}

The construct social capital has received a tremendous amount of attention in the field of sociology in recent years. Sociological Abstracts identifies 212 items with the key word social capital since 1999. No fewer than five books were published on the topic in the first six months of 2001 (Baron, Field, and Schuller 2001; Cohen and Prusak 2001; Edwards, Foley, and Diani 2001; Lin 2001; Lin, Cook, and Burt 2001). Perhaps so much has been written in part because there is no clear consensus what exactly social capital is. A dozen years and more after those most cited for its definition provided us with one (Bourdieu 1983; Coleman 1988), experts are still writing entire articles defining social capital (Lin 2000; Portes 2000), and sections titled "What Is Social Capital?" in empirical reports and chapters on the subject seem to be de rigueur (Coleman 1988:S97-S100; McNeal 1999:119-20; Paxton 1999:91-97; Renzulli, Aldrich, and Moody 2000:524-30; Schiff 1992:159-61). It is difficult to imagine similar confusion in other fields - a status attainment article with a section called "What Is Income?" or a demography article with one called "What Is a Birth?" Paxton (1999:90) observes that "the term social capital is used in many recent articles but in vastly different ways." Everybody knows social capital when they see it, but the field cannot agree on a common definition.

What is the source of disagreement? Capital is any commodity that helps individuals achieve some goal. Social capital inheres in relationships between individuals, just as physical capital inheres in physical objects and human capital inheres in humans. Thus, social capital is any commodity that inheres in relationships between individuals that helps them achieve some goal. But what is the goal of human

\footnotetext{
*Direct correspondence to: Joanne Savage, Department of Justice, Law and Society, American University, 4400 Massachusetts Avenue, NW, Washington DC 20016-8043. (202) 885-2974. E-mail: jsavage@american.edu.
} 
behavior? What do humans want? Why do we behave at all? We believe that the failure to specify the motivation for human behavior is at the root of the dissension.

Any commodity can be capital, depending upon the goal one has. If one's goal is to run an efficient drug market, then guns and ammunition are important physical capital, the ability to distinguish between high- and low-quality drugs is important human capital, and connections to corrupt cops in the precinct are important social capital. None of these commodities qualify as capital if one's goal is to earn an M.B.A. from Harvard Business School. In fact, we probably could propose unique definitions for capital for every individual human being if we rely on one's circumstances to define one's needs. If we wish to understand social laws governing human behavior generally and to identify which commodities qualify as capital in social relationships, we need to identify goals common to all human beings. If we do not know what goals are common to human beings, we do not really know what social capital is, and if we do not know what it is, we cannot measure it precisely or expand our understanding of its role in social life.

The problem of defining social capital is therefore largely a problem of understanding human goals. There is a long line of theoretical work related to motivation in social relationships (Turner 1987), but the vast majority of contributions forward no plausible proposal for why humans behave that is grounded in the biology of the human species. We turn our attention to evolutionary psychology, which we believe is currently the only contender for a general theory of values (Kanazawa 2001a). The evolutionary psychological approach is the only general theoretical perspective that attempts to explain the ultimate (as opposed to the proximate) causes of human behavior, cognition, preferences, and emotions. This approach therefore will be used here to inform a revised definition of social capital and its basis in innate psychological systems.

One of the major criticisms of papers about evolutionary psychology is that they fail to make the link to known human neurophysiological systems. We will attempt to remedy this problem by reviewing the relevant literature from the social and neurological sciences that we use as a basis for our propositions. We then will turn to the matter of sex differences in sociability and to their importance for understanding the construct of social capital and will discuss related empirical literature there as well. Finally, we will discuss the utility of the revised definition of social capital and will discuss some examples.

We wish to make it clear that this article is written for a sociology audience. We make the case for genetic bases of social behavior and biologically based sex differences in sociability, assuming the reader is familiar with and is predisposed to focus on cultural and environmental causes of behavior. In reality, we believe the two realms complement each other and that human behavior cannot be understood fully without comprehending both biology and environment. However, this article was inspired by our observation that a major gap exists in the sociological literature with respect to the role of biology in human social behavior, so we strongly emphasize that here.

\section{PRINCIPLES OF EVOLUTIONARY PSYCHOLOGY ${ }^{1}$}

Because evolutionary psychology (EP) is an emerging theoretical perspective and because sociologists in particular are unlikely to be familiar with it, we will present

\footnotetext{
${ }^{1}$ Excellent introductions to evolutionary psychology include Cosmides and Tooby (1992), Buss (1999), Cartwright (2000), Ridley (1993), and Wright (1994).
} 
first the foundational principles of EP before using the perspective to define social capital. Evolutionary psychology is the study of universal human nature, which is a collection of domain-specific evolved psychological mechanisms. An evolved psychological mechanism is an information-processing procedure or decision rule with which evolution by natural and sexual selection has equipped humans in order to solve a particular adaptive problem (a problem of survival or reproduction). Unlike decision rules in microeconomic subjective expected utility maximization theory or game theory, however, evolved psychological mechanisms mostly operate behind and beneath conscious thinking.

As with evolutionary processes that led to the development of other parts of the body, adaptive problems during the course of human evolutionary history are expected to have led to the evolution of the brain. Natural and sexual selection are thought to be the principal mechanisms through which this evolution has occurred. Natural selection refers to the process of differential survival; sexual selection refers to the process of differential reproductive success. Individuals who possess certain psychological mechanisms live longer (because the psychological mechanisms help them survive) and reproduce more successfully (because the psychological mechanisms help them find mates). Those with particularly adaptive psychological mechanisms out-reproduce those without them in each generation, and more and more individuals come to possess the selected psychological mechanisms over generational time. Eventually, all individuals come to possess them, and they become part of universal human nature. Evolved psychological mechanisms are thought to engender desires, values, preferences, emotions, and other internal states that serve as proximate causes of behavior.

Animal hunger is an example of a not-very-controversial evolved psychological mechanism. Procurement of sufficient calories to sustain the body physically has always been necessary for survival. Those who know when to eat are better off physically than those who do not. The evolved mechanism of hunger-whereby the brain interprets information from the biological self and translates it into a conscious or unconscious desire to eat or a compulsion to do so-ensures that animals will rarely starve to death if food is available. Those possessing the hunger mechanism therefore have lived longer, have led healthier lives, and have produced higher-quality offspring than those who did not. They in turn passed on the mechanism to their offspring. This process repeated itself over many thousands of generations, until virtually all higher animals have the ability to detect when food is needed and respond with the desire to eat (see Buss 1995:5-9 for other examples of evolved psychological mechanisms).

Evolutionary psychology is premised on two broad generalizations. The first generalization, to put it bluntly, is that there is nothing special about Homo sapiens. To put it more precisely, human beings are just like other animal species, and all the laws of nature - in particular, the laws of evolution by natural and sexual selection - apply equally to humans as they do to other species (Kanazawa 2001b; Maryanski and Turner 1992). The second broad generalization is that there is nothing special about the brain as a human body part; it is just like the hand or the pancreas or the eye. Just as a long history of human evolution has shaped the hand to perform specific functions, so evolution has shaped the human brain to perform certain tasks.

The second generalization leads to a very important implication of EP. Just as the basic shape and functions of the hand have not changed since the end of the Pleistocene epoch about 10,000 years ago, the basic functioning of the brain has not changed very much either. The human body (including the brain) evolved over millions of years in the African savanna where humans lived in small bands of 50 
or so related individuals as hunter-gatherers ${ }^{2}$ (Maryanski and Turner 1992). This environment is referred to as the "environment of evolutionary adaptedness" (EEA) (Bowlby 1969) or ancestral environment, and it is thought that it is to the EEA that the human body (including the brain) is adapted.

Evolutionary psychology strongly rejects the view of the human mind as a tabula rasa and avers instead that it is content-rich and biased. The human brain and all of its psychological mechanisms are adapted to enhance reproductive success. This "law of human nature" or theory of values and human motivation, can help us explore the concept of social capital by addressing the missing component in current theoretical work - namely, the goals of behavior.

From the EP perspective, reproductive success (RS) is the force that has shaped the values and preferences that humans hold in common today. The connection between reproductive success and contemporary goals and motives for behavior is not an easy one to grasp and critics of "fitness" arguments often mistakenly impose a conscious constraint on the process. We wish to be very emphatic here: although we sometimes use shorthand to refer to reproductive success as a "goal," it is clear that conscious desires are not what evolved to enhance $\boldsymbol{R S}$. As Daly and Wilson (1988:7) point out: "Evolutionary psychology is not a theory of motivation. No one imagines that genetic posterity (fitness) is a superordinate 'goal' in any direct sense." What did evolve, in all probability, are fairly simple physiological reactions to certain stimuli that shape our behavior, and those physical reactions are expected to be consistent with reproductive success. In other words, for EP to be a valid theory, humans do not need consciously or even unconsciously to value reproductive success - they do not need to "want" children, "want" to have sex, or even "want" to live. But the things they will like, or be interested in, or find unpleasant - and most of the things that successful cultures come to value - will be consistent with individual reproductive success on a much greater than chance basis. For example, a libidinous response to certain situations (being touched in an erogenous zone) often occurs without conscious control and clearly favors reproductive success. There are a vast number of other mechanisms that could be proposed where anxiety, pain, or pleasure are associated with a variety of situational stimuli (the view from the edge of a cliff, the sight of a snake or spider, the cry of a baby) and where such responses enhance reproductive success because they motivate behavior that secures it. Because humans are adaptable to their environments and are amazing learners, there will not be a 100 percent corroboration between what evolutionary science would predict and how humans actually behave. The fact that humans commit suicide, choose same-sex sexual partners, and take birth control pills, for example, suggests that experience and learning play an enormous role in our behavior. But this does not mean that underneath it all we have no common "nature"-it simply suggests that our nature includes mechanisms that allow us to adapt easily to situations.

Although we emphasize reactions that are common to humans generally, variability and changes over time are still expected because these processes are likely to be affected not only by genes related to characteristics common to all humans, but by other genes that vary more significantly from person to person. Further, the processes we are

\footnotetext{
${ }^{2}$ As a first approximation, it might be useful to think of the EEA as the African savanna during the Pleistocene epoch, because this is indeed where many psychological mechanisms evolved. Technically, however, the EEA might be different for different adaptations (Tooby and Cosmides 1990:386-87). In order to pinpoint the EEA for a particular adaptation, we need to consider the entire period of evolution from the time when we did not have the characteristic (which may have been before we were human) until the time when all humans had it. Humans share a large proportion of genes with apes, but we also share a large percentage with tulips.
} 
discussing are biological in nature and may be affected by nongenetic biological factors such as diet, hormones, toxins, illness, and so on. Finally, among humans, learning and environment affect behavior of any kind - and learning and behavior also change brain functioning so that physiological responses to situations may change after they are experienced. I may start my life having a very strong fear reaction to spiders; as I learn that the spiders I encounter do not harm me, that reaction should lessen in magnitude.

The preference for sweets is an example of a psychological mechanism that is believed to have evolved among humans (Barash 1982:144-47), but it varies from human to human. This variability should not be taken as convincing evidence that the trait is not common to all individuals. Homo sapiens are identified by characteristicstwo arms, two legs, two eyes, and so on-that derive from genetic material common to all humans. Anyone would agree that humans are characterized by having arms, yet there is a lot of variability in the human arm; some are muscular, some are hairy, some have scars. These differences are due to other genes, other biological influences, and other life experiences. Just because all arms are different does not mean that humans are not characterized by having arms. The evolutionary psychological view suggests that there are also features of "humanness" embedded in the biological functioning of our brain. We get hungry (some people more than others); we feel sexy (some in response to different stimuli than others); and, in this article we will argue, we respond in predictable ways to various types of contact with other humans - we are social.

With this theory of human "motivation" in hand, we can proceed to our discussion of social capital.

\section{SOCIAL CAPITAL FROM THE EVOLUTIONARY PSYCHOLOGICAL PERSPECTIVE}

In this section we present a revised definition of social capital, consistent with evolutionary psychological theory, and discuss the premises for that definition: human sociability is innate; predictable sex differences exist in sociability; humans are likely to value relationships that enhance their reproductive success - those characterized by "social capital."

\section{Definition}

Social capital from the evolutionary psychological perspective is any feature of a social relationship that, directly or indirectly, confers reproductive benefits to a participant in that relationship. ${ }^{3}$ Based on the principles of natural selection and sexual selection discussed previously, a relationship that constitutes capital is one that promotes and does not hinder one's ability to survive, to mate, and to promote offspring to sexual maturity. We believe that humans are innately social and that humans are genetically endowed with tendencies to respond to particular social cues that indicate capital in the sense we have defined it here. We believe most humans therefore are likely to develop individual preferences for such relationships and that cultural values, beliefs, and practices in most societies are consistent with these preferences. In order to bolster support for these propositions we review evidence from several fields regarding

\footnotetext{
${ }^{3}$ Reproductive success includes not only the individual's own reproduction (classical fitness) but the reproduction of his or her close kin (inclusive fitness).
} 
human sociability and some of the mechanisms in the central nervous system through which it may operate. We also will spend some time discussing emotional responses to social stimuli, which we believe are likely to be the principal mechanisms through which human sociability develops.

\section{INNATE SOCIABILITY}

The anthropological record suggests that early humans lived in small bands, and a quick glance at human ecology over the earth today suggests that humans have a strong preference for living in close proximity to other humans, not for being isolated from them. Such a strong tendency throughout the world and over time suggests that the human mind has been designed with preferences for companionship, and we take it as evidence that humans are innately social.

The observation that humans are "sociable" is consistent with what would be predicted based on what we know about the environment of evolutionary adaptedness (EEA). Food was often scarce, and food sharing and other cooperative activities probably were critical to survival (Hrdy 1999). One could speculate easily that genes associated with enjoying the company of others, with getting along with others, and with experiencing anxiety when in conflict with others were associated with survival and persisted in our species.

Other authors have drawn a link between evolution and social relationships. For example, Turner (2000) (see also Maryanski and Turner 1992) suggested that when our early ancestors were forced to move from the forest (where they existed as a rather asocial and independent species) to the savanna, it became important for them to develop closer social ties: "Highly structured social relations would be fitnessenhancing because group-oriented primates could gather and share food collectively, while coordinating activities to defend a comparatively slow and weak animal from predation" (2000:33).

\section{Research on Sociability}

If human sociability is innate, it must be physiologically based, at least in part, and burgeoning research suggests that it is. For example, Geary and Flinn (2002) cited several studies that support the role of hormonal factors in paternal and maternal investment among primates. High cortisol levels are correlated with attentive and sensitive parenting, as are prolactin levels and testosterone (in males). Turner (2000) pointed out that apes have few social ties but are able to communicate with facial gestures. He also cited several studies that suggest there are specialized neurons for visual recognition of the emotions revealed by the face in monkeys. Kendrick and Baldwin (1987) report that even the temporal cortex of sheep responds preferentially to the sight of faces. The ability to recognize faces also has been demonstrated in rhesus monkeys.

Ekman $(1973,1992)$ offered substantial evidence for universal facial expressions in humans, which implies a genetic basis. The human face has vast numbers of striated muscles that control expressions and is heavily laced with blood vesicles that expose autonomic responses such as blood flows that can be read and interpreted by others (Turner 2000). The functionality of these muscles and blood vesicles in the communication of emotions to other humans seems obvious - it is not clear what other functions these muscles and blood vesicles have. 
Humans also are equipped to respond to facial expressions. De Haan and Nelson (1999) cited evidence that the visual recognition system in humans responds differentially to faces compared to other objects. George et al. (1998) suggested that normal subjects use the right insula and bilateral anterior temporal and prefrontal cortices to recognize emotion expressed in a human face. The inability to assess facial expressions in others accurately has been seen in persons with brain diseases and brain damage (Geschwind 1979; Halligan 1998; Mandal, Asthana, and Maitra 1998). Geschwind (1979:113-14) pointed out that "it may seem that a disproportionate share of the brain's resources is being devoted to a rather limited task [recognizing faces]. It should be kept in mind, however, that the recognition of people as individuals is a valuable talent in a highly social animal, and there has probably been strong selectional pressure to improve its efficiency."

\section{Sociability and Emotional Responses to Social Stimuli}

The most obvious candidate for a mechanism that shapes human sociability is the emotional system mediated by the brain. LeDoux (1996) pointed out that emotions are powerful in shaping human behavior. It has been suggested that the key to forging social bonds, which was essential to survival in the African savanna, was gaining control over and expressing emotions (Turner 2000). Turner reasoned that in order to survive in the savanna, humans had to form strong social bonds; in order to do so, we first had to gain some degree of control over the noisy subcortically generated emotions we had inherited from our ape ancestors and then to expand our ability to communicate a wide variety of emotional dispositions.

We propose that human sociability originates in neurochemical responses to certain social stimuli that are experienced as emotion - anxiety or pleasure, for example. Building on Turner's (2000) theory, we suggest that humans developed neurochemical responses to specific social cues such as a baby's cry, facial expressions such as smiles or frowns, loud yelling, insults, and the like, which, experienced as positive or negative emotions, influenced behavior. Those individuals who experienced negative emotions in response to loud yelling, for example, would have been motivated either to settle the conflict or to leave the situation-both of which probably would have been associated with better reproductive success than doing nothing. Similarly, those individuals who experienced pleasure in the company of others - at the sound of a human voice or in response to human touch, for example-would have been motivated to persist in social behavior. Those individuals who were indifferent to human company would have dramatically increased their chance of mortality by straying from the group and becoming vulnerable to the dangers of wild animals, aggressive hominids from other bands, or starvation. Those individuals endowed with mechanisms that associated social stimuli with behavior-modifying emotion would have had a better chance at reproductive success.

The exact genes and associated structures and mechanisms of the emotional basis of sociability have not been cataloged, but there are certainly some functional areas of the brain thought to be associated with human sociability and emotionality that could have evolved through the process of natural selection, for example, the attachment process between infants and caregivers. Dopamine neurons in the ventral tegmental area of the anterior reticular formation, for example, may be responsible for a reward response (dopaminergic-driven arousal) seen in infants at the appearance of the mother's face in dyadic play (Schore 2001). The anterior 
cingulate gyrus, too, has been linked with attachment behaviors such as the cry of separation. These and other structures could have become specialized through natural selection.

\section{Research on Central Nervous System (CNS) Responses to Social Stimuli}

If our proposition is correct, there should be measurable associations between certain social stimuli and certain emotional responses. There is strong empirical evidence that both men and women derive positive emotions from successful exchanges with others (Lawler, Thye, and Yoon 2000; Lawler and Yoon 1998). Studies of the central nervous system have only just begun to document mechanisms of emotion and reward systems in the brain (e.g., Derryberry and Tucker 1992; Routtenberg 1978) and have begun to locate those systems (Reiman et al. 1997; Turner 2000; see also George et al. 1995). The burgeoning literature on neurological responses to social stimuli suggests that when our perceptual system detects specific social stimuli, the brain responds by increasing blood flow or excreting neurotransmitters that cause pleasure or anxiety. For example, Kampe et al. (2001) reported that returned eye gaze from an attractive face is associated with increased activity in the ventral striatum, which is associated with reward. In their efforts to discover neurological bases of emotional temperament, Davidson and Fox (1989) found that greater right frontal activity in electroencephalograph (EEG) during baseline measurement was associated with a greater likelihood of crying in response to maternal separation in a sample of normal 10-month-old infants. Lane et al. (1997) showed subjects films, some of which depicted emotioneliciting social situations (a joyous romantic reconciliation and grieving for a friend who had committed suicide) and found that happiness, sadness, and disgust each were associated with increases in activity in the thalamus and medial prefrontal cortex. These findings are consistent with the supposition that humans generate emotional responses in response to some social cues.

\section{DETECTING SOCIAL CAPITAL}

In addition to the development of sociability more generally, it also is likely that humans have developed psychological mechanisms that cause us to prefer relationships that will increase the probability of our reproductive success (will constitute "capital") and to avoid relationships that will diminish it. One can easily see how, in the ancestral environment, it would have been adaptive to pick and choose social investment carefully. Those who invested in relationships that enhanced reproductive success would have been more likely to survive and to reproduce; those who wasted efforts on persons who were too much of a burden might lose out. As Beck (1999) pointed out, having keen sensitivity to the dangerousness of others might have saved us from harm. One can see why it would have been useful to detect cheating (as it is today), and there is evidence we can (Cosmides 1989; Cosmides and Tooby 1992). It also might have been useful to identify cues that indicate that a person is of high social status, is healthy, is talented, has significant material resources, or sincerely likes us. There is a line of research suggesting that when humans are interested in something, our pupils dilate and that when we see a face with dilated pupils, we like that face more. We hypothesize that the perception of cues relevant for assessing the "social capital" potential of a relationship result in increased pleasurable or anxiety-provoking neurochemical responses in the brain. 


\section{SOCIAL CAPITAL AND SEX DIFFERENCES IN SOCIABILITY}

Much of the research and theorizing on social capital has focused on sex differences in social capital and in the use of social capital for positive life outcomes. The differential findings across sex have caused some confusion in the field. One implication of a perspective that includes sexual selection as an important feature in the evolution of psychology is that what counts as social capital is likely to be different for men and women. Therefore, it would be likely that we would find differences in kind or degree of psychological mechanisms related to detecting and/or responding to social capital.

There is a vast literature on sex differences in a wide variety of fields, and it is clear that males and females vary on numerous dimensions. The extent to which such differences are biological or cultural is still a matter of debate. We propose here that an important innate difference is the extent to which women and men experience pleasure or anxiety in response to certain social cues. We propose that on average, women experience more pleasure in close personal relationships and more anxiety at their loss than men do, though we expect that, ultimately, the dynamics will be much more complex than that. We propose that a significant contributor to the differences we find in social style in males and females is the differential neurochemical responsivity of the brain. After discussing why sex differences in sociability would be anticipated by the evolutionary psychological view, we will explore some of the empirical literature on sex differences in social relationships, brain anatomy, and neurophysiology that demonstrate that our hypothesis is plausible. Then we will return to our discussion of social capital, its changing nature, and its redefinition.

\section{Why Would There Be Innate Sex Differences in Sociability?}

In order to propose that there are innate sex differences in how male and female humans perceive and experience social relationships, it is necessary first to consider how life for males and females in the EEA is thought to have differed. We will explore several differences in lifestyle that we believe led to the evolution of differential responsiveness to social cues.

There is evidence that food sharing was of critical importance to both males and females in the EEA, so it is likely that some level of cooperation and sociability evolved for both sexes. But the way that males and females went about feeding themselves varied to some degree. Although males and females are likely to have shared with one another, it is widely believed that the division of labor in the EEA was such that women devoted their time to caring for children and food gathering (Hrdy 1999), while hunting is thought to have been predominantly a male activity. It has been argued that this division developed in part because women were burdened by gestation, postnatal care, and infant dependence on mother's milk (Harper and Sanders 1978). Further, because a society depends on the number of females for its repopulation, it is thought that societies where women risked their lives hunting would have had problems with dramatic population attrition. Of course, it is unlikely that there was a completely consistent line of differentiation between the food-gathering behavior of males and females in the EEA. But if fairly stable patterns of sex differentiated roles existed over the period of time in question, subtle differences in social behavior could have evolved.

This division of labor is thought to have promoted different social behaviors in males and females. For example, it has been proposed that hunting involves more travel and cooperation. Harper and Sanders (1978) used the analogy of wolves and 
wild dogs, whose fitness clearly is enhanced by closely coordinated group behavior. Geary and Flinn (2002) argued that alliance formation was a crucial element of the social life of men in preindustrial societies. Over time it is thought that men's relationships came to reflect a balance of cooperative and competitive behavior: "Cooperation is needed to maintain the coalition, and competition emerges from attempts to increase individual status within the dominance hierarchy" (Geary and Flinn 2002:74). ${ }^{4}$

It also has been pointed out that sex differences in sociability may have occurred due to male philopatry (Geary and Flinn 2002). Unlike most other primates, male humans in the EEA were the philopatric sex (remained with the natal group), while females emigrated when they reached adolescence. Because females emigrated to nonkin groups the relationships they developed would require greater reciprocity and equity than those of males (Geary 1998). Males, in contrast, benefited from kin bias or inclusive fitness (Mealey 2000). Maintenance of kin relationships does not require the same level of reciprocity and effort as relationships with nonkin do. This implies that males would not have needed to develop the subtle social competencies that females would have needed.

Another source of sex differences in sociability probably is due to differential parental investment based on sexual selection. In species with internal gestation and postpartum maternal care such as nursing in mammals, females can produce considerably fewer offspring than males can (Geary 2002). Therefore, they have more incentive to be choosy about mates than males do and are likely to invest a great deal of effort in parenting offspring to reproductive age. Hrdy (1999) describes the conditions in the Pleistocene Epoch, estimating that the vast majority of women got pregnant and had babies, but the majority died without leaving a single child that survived to maturity because of the difficult environmental conditions. Under such circumstances, we would expect that females who responded intensely to cues from their babies would have greater reproductive success than those who did not, and many believe that maternal instincts developed during that time and persist (Hrdy 1999). Although it certainly would be fitness enhancing for fathers to respond to cues from babies, their reproductive success was not linked as closely to the survival of any particular baby as that of the mother; we would not expect their neurological responses to the perception of infant social cues to be as strong.

Another source of sex differences in sociability comes from the need for resource acquisition and status enhancement in males. While the reproductive success of human females is closely linked to a few children and, therefore, maternal investment is high, male reproductive success is limited only by the number of mates that can be

\footnotetext{
${ }^{4}$ One reviewer suggested that it seemed "suspicious" that because men are more competitive today, we infer that the ancestral environment favored competition for men but not women-when it seems plain that women could have competed for food, mates, and other resources. Our response is first that the modern view of competition is not that females are not competitive at all-just less competitive than males (Maccoby 1998). Second, the reasoning that males are more competitive today is based on the proposition that status attainment has greater reproductive benefits for males than females. Males could increase their reproductive success by expending energy to attract more mates (because they are capable of producing an unlimited number of offspring), while females are better off being more selective about mates and choosing mates based on their health, resources, and status (because they can have a only limited number of offspring and their reproductive success is tied more closely to the survival and well-being of any individual child). Thus, although females certainly had something to gain by acquiring resources, they had less to gain than males did by competing for them once they had what they needed. Modern-day examples of this disparity abound. One cannot help but notice the absurdity of the tendency for competition for resources beyond those needed when one hears about the multi-hundred-million-dollar salaries of (almost exclusively male) American chief executive officers (CEOs).
} 
found. Although the reproductive success of males can be increased by paternal investment in children, it also can be enhanced by ignoring children and by investing time and energy acquiring resources and building social status, which are associated with finding more mates (Kenrick et al. 1990; Trivers 1972). In many species, paternal investment is low. Geary (2000:55) noted that "in more than 95\% of mammalian species, males provide little direct investment in the well-being of their offspring." Human males are comparatively paternal. Nevertheless, among humans paternal investment is "facultative," varying more than maternal investment and depending on paternity certainty, alternative mating opportunities, and the strength of the relation between paternal care and offspring survival (Geary 2000). Research suggests that wealth and status have been associated with more wives in some cultures, more pre- and extramarital liaisons, a greater probability of remarriage after divorce or widowhood, and the ability to attract a younger wife (Mealey 2000 cites a series of studies on this issue) and also suggests that males invest more of their effort toward enhancing status and making money (Pratto, Sidanius, and Stallworth 1993).

Finally, we would expect that females, who were smaller and less able to physically defend themselves and who became pregnant and had babies, would have benefited to a great degree from strong social relationships. Pre-, peri-, and postnatal survival for mothers, their babies, and orphaned children almost certainly depended on getting help from others. It is reasonable to postulate that females would have developed a strong set of psychological mechanisms that foster the establishment and maintenance of social relationships that would help them with these tasks and difficultiesmechanisms that result in the acquisition and maintenance of "strong ties" from which larger favors can be expected. Because early human social groups often were divided by sex-females gathering food together, males hunting together-and because females were designed to give more attentive infant care than males, it is likely that strong female-female social bonding would have been highly fitness enhancing for women in the ancestral world.

\section{Proposed Sex Differences in Human Social Response}

Given the evidence, we expect that women will find close personal relationships more pleasurable than men will and will experience more anxiety when those relationships are threatened. Women also will value relationships that can help them promote the well-being of their offspring more than men will, such as female-female friendship bonds. Men, on the other hand, will be more inclined to develop a larger network of weak ties. They will be less inclined to invest a great deal in intimate personal relationships than women will, or in their children. Women are expected to have greater social competencies, such as increased sensitivity to the emotional status of others and greater pleasure or anxiety in response to happiness or distress in others because of their experience in the EEA, where they left their natal group and are thought to have needed to develop fine-tuned social skills for getting along with nonkin. Males are expected to be more cooperative - teamwork, for example (due to the need for cooperative behavior in hunting) - yet also more competitive-more interested in the enhancement of their own status and material resources (due to sexual selection). Consequently, the pleasure males experience when forging a relationship with a high-status other or another person holding material resources is expected to be greater than that for females (holding constant the extent to which the status can help promote the female's offspring). 


\section{RESEARCH ON SEX DIFFERENCES}

In order to establish that males and females have innate differences in their CNS responsiveness to social relationships, we would need to establish first that the manifestation of social relationships is different and second that the brains have anatomical or neurochemical differences resulting in differential responsiveness to social cues. This is particularly difficult to establish since, as the social psychological literature long has established, boys and girls typically are subject to differential socialization practices beginning early in life. Socialization could cause differences in behavior, and both socialization and behavior do affect later brain responses. Unfortunately, adequate research for establishing each premise as we have proposed it does not exist. However, the research that does exist on sex differences in sociability and brain neurochemistry generally is supportive of the view proposed here. Following, we discuss some of the research related to these issues to give the reader a sense of what needs to be done in this area to test our hypotheses.

\section{Sex Differences in Behavior}

The interpretation of the literature on sex differences appears to be a "glass-halfempty" problem: there are sex differences in behavior; they are smaller than we would expect if we were to believe that males and females are terribly different and are unable to adapt to situations; and this has led some to downplay the differences and to emphasize the similarities. Nevertheless, if we assume that like-brained individuals should have no differences, the number of differences and evidence of their early onset is highly suggestive of innate differences versus those that are due purely to socialization. In spite of early reticence to emphasize biological differences between the sexes (Maccoby and Jacklin 1974), Maccoby's (1998:9) recent review stated that starting in 1960 s and 1970s accumulating research began to indicate that the "socialization model" of sex differences was "too narrow, too limited." The early review concluded that female hormones play a role in maternal behavior and that mothers are more inclined to display nurturant behavior with infants than fathers are. The authors suggested that one of the most solidly established sex differences is that girls have greater verbal ability than boys (corroborated by more recent reviews, e.g., Geary 1998) - a skill related to social interaction. That review and many subsequent ones confirmed that males are more aggressive than females (e.g., Mealey 2000) and that this difference is evident as early as age three (Maccoby 1998). There are differences in male and female friendship groups; boys typically have more friends and girls have fewer but more intimate friendships. Girls are more likely to offer social support (across six cultures studied)

Maccoby's (1998) more recent review expanded upon these themes. She now concludes, for example, that gender homophily begins by age three (see also Geary 1999) and that it is boys who are more active in establishing and maintaining the separation of the sexes. By first grade, boys show a strong orientation toward other boys. Boys are more physical in their play activities and tend to play in reduced proximity to adults (compared to girls), closing ranks with other boys to protect each other from adults when they conduct their risky, limit-testing enterprises (Maccoby 1998:53). Maccoby (1998:37) points out that it is worth emphasizing "how much fun boys have together." She suggests that boys appear to be using their rough and tumble encounters to establish a dominance hierarchy. Maccoby pointed out that boys engage in dyadic play like girls do, but they also are greatly involved in "coordinated group activity" with 
larger groups of peers, which is much less common among girls. Maccoby concluded that boys are more competitive than girls and describeed a study where competition characterized 50 percent of observed free play activities among boys but only 1 percent among girls. Maccoby (1998:56) suggests that the culture of boys groups is very distinct when compared to that of girls, the major difference being that boys are involved more intensively in issues of dominance and maintenance of status.

Girls, by contrast, are thought to dislike the rough play style of boys and withdraw from it (Maccoby 1998). There is some evidence that the tendency for girls to play in closer proximity to an adult is limited to times when boys are around, "operating under the assumption that, when boys were present, having an adult nearby made them safer" (Maccoby 1998:63). Girls' friendships are more intimate than those of boys, including more mutual self-disclosure, physical closeness, and eye contact. "Thus," Maccoby (1998:55) concluded, "we see precursors to the kind of social lives children lead in the middle childhood years, with girls concentrating mainly on reciprocated friendships, while boys invest in two kinds of social relationships: their larger male groups and their same-sex friendships."

Geary (1999:118) concurred with Maccoby's characterization of boys' and girls' play activity: "The social behavior of boys is focused on achieving status and dominance and developing coalitions for competing against groups of other boys.... The social behavior of girls is focused on developing and maintaining a network of personal relationships and social support."

Other research unearths further evidence of sex differentiation in behavior. Geary (1998) concluded that females are more sensitive to nonverbal communication than males. Consistent with our link between sociability and emotions, Geary (1998:173) argued that "in comparison to men, the greater emotional reactivity of women might then complement a greater sensitivity to the social cues and the nuances of social relationships. In combination, these competencies will provide women with a relative advantage in managing social relationships."

Some authors maintain that women have stronger social bonds (Deaux 1976; Mitchell 1981). According to Mitchell (1981), among middle-aged persons women's relationships appear to be stronger, more spontaneous, and more open than relationships among men. Men get together with friends for a reason; women just get together. "Women report more positive feelings about being close to others, even about physical contact, than do men" (Mitchell 1981:95). Others have found that girls are more altruistic (Skarin and Moely 1976) and experience more distress related to the problems of others (Hayes 1991). Taylor et al. (2000:418) pointed out that, under conditions of stress, "the desire to affiliate with others is substantially more marked among females than among males" and that this is "one of the most robust gender differences in adult human behavior." Marshall and Heslin (1975) found that the effects of group size, density, and composition had different effects on the positive feelings males and females had about the group.

The giving and receiving of emotional support is another aspect of sociability where we observe sex differences. In a meta-analysis on sex differences in coping, Luckow, Reifman, and McIntosh (1998) (as cited in Taylor et al. 2000) found that the largest difference was that of seeking and using social support. Wellman and Wortley (1990) examined a series of personal characteristics such as education, employment, occupational status, marital status, and age and found that gender was the only personal characteristic directly related to emotional support; women provided more emotional aid than men. In their study mothers and daughters were the most apt to provide emotional support, followed by sisters. Women in the sample also received a great deal 
of emotional support from friends and neighbors. Men, who rarely have women friends or acquaintances in their social networks, obtain their emotional support from mothers and sisters. Hayes (1991) emphasizes that for women, social relationships are not always beneficial. Her review shows that women are far more concerned with the problems of those in their social networks, are more likely to give help (for example, in an acute medical crisis), are more likely to help elderly relatives, and so on. Women therefore are more susceptible to the demands of social relationships than men are, and Hayes focuses on the balance of gains and losses in women's interactions with others.

If sexual behavior can be seen as a gauge of sociability, then males are more "sociable" than females by numerous measures. For example, the earliest Kinsey reports (Kinsey, Pomeroy, and Martin 1948; Kinsey et al. 1953) suggested that more males engage in premarital sex, extramarital sex, and homosexual contact than females, and more recent studies corroborate those estimates (Mealey 2000). Laumann and Youm (2001) reported that men are less likely to be categorized in monogamous classes, and Waite and Joyner (2001) found that men were much more likely than women to rate having sex with more than one person at a time or having sex with a stranger as "appealing." Many authors have noted that the two sexes evaluate sex partners differently (Mealey 2000). Based on a variety of studies, Mealey (2000) concluded that males are more likely to exhibit "mate guarding" - preventing a female from access to other males - and although women occasionally use similar tactics, the more coercive are limited to a great degree to men.

There is some evidence that mothers and fathers behave differently with their offspring. Maccoby (1998) cites "thoroughly documented" evidence that women assume most of the day-to-day responsibilities for child care in all known societies. Evidence suggests that fathers are less verbal and engage in more boisterous activity with their children (Maccoby 1998; Mealey 2000). Wellman and Wortley (1990) suggested that fathers in their study were almost as emotionally supportive as mothers but showed their support by doing things rather than by saying things, though Maccoby (1998) concluded that fathers are more likely to use unqualified imperatives ("do it now"), to call children names, to interrupt children, and to make disparaging remarks. They tended to have more specific expectations of their children based on sex (Maccoby 1998; Wellman and Wortley 1990) and were more likely to influence sex-role socialization than mothers. Fathers generally are more involved in rearing sons than daughters if we look cross-culturally.

Because of the prominence of research on the dynamics of social capital, social networks, and status attainment, the research on social networks is particularly relevant for this article. Among adolescents and adults, there is evidence that social networks are subtly different for men and women. Various authors cite evidence that the social or business networks of men and women are of similar size, but where different, men's networks are larger. Although sex differences in the character of social networks have not been examined in great depth, it appears that women's networks are composed of a larger proportion of kin than men's networks are (e.g., Campbell 1988; Moore 1990). ${ }^{5}$ It is important to point out that our understanding of

\footnotetext{
${ }^{5}$ The reader may wonder if the fact that women have a larger proportion of kin in social networks in modern times is inconsistent with what was said earlier in the article about males being the philopatric sex. Perhaps because humans in modern societies no longer live in small "bands," societies no longer are characterized by the tradition of individuals emigrating from their natal group to prevent inbreeding. We cannot think of any reason why men would have developed a greater preference for kin than women would have simply due to philopatry - in both cases ties with kin are likely to increase reproductive success. So we think that the fact that in modern times women have more kin in their social networks is due simply to the differences in preferences for closer relationships and for a greater valuation of "social capital" related to promotion of offspring among women.
} 
male-female differences in social networks is not due completely to limited measurement employed in these studies: None really delve into the quality and character of social relationships within networks, which certainly could be different for men and women.

The dynamics of social networks also appear to be different for men and women, though, again, the research is very limited. Campbell (1988) and later Munch et al. (1997) found that having a young child was related negatively to network range or network size for women but not for men. Munch et al. (1997) pointed out that the character of men's networks did change - to include more kin - when they had small children. Of interest in the area of social capital, Burt (1998) found that network size was related positively to early promotion for men but had the opposite effect for women, for whom fewer network connections was related to earlier promotion. Renzulli, Aldrich, and Moody (2000) found that female "nascent entrepreneurs" (persons seriously trying to start a business) had a higher proportion of kin in their networks and that a higher percentage of kin was related to a reduced chance of successfully starting a company. Lin (2000) summarized the literature by saying that it is "quite clear" that males have larger networks, are affiliated with larger associations, and enjoy the benefits of associating with other males (since males occupy higher positions in hierarchical structures); and females are affiliated with "disadvantaged networks," which are smaller, less diverse, and contain more females. Although Lin acknowledged that few studies provide data on the relative returns of social capital for males and females, he suggested that although social capital helps explain differences in female outcomes, even when males and females have relatively equal capital they have different status outcomes.

\section{Sex Differences and the Central Nervous System}

It should be pointed out - and many authors have emphasized - that sex differences in behavior or skills can be a result of socialization. In order for our proposals to have merit, some, but not necessarily all, of the differences in behavior between males and females must be a result of innate differences in central nervous system biophysiology. Again, we point out that extant research is not adequate to establish the empirical validity of our view, but the research that does exist supports the propositions we make here. We discuss some of the relevant studies.

\section{Brain Anatomy and Neurophysiology}

As Breedlove (1994) pointed out, there are no behaviors that are strictly a result of environment or of biology. The interaction among brain neurochemical effects on behavior and experience is ongoing and reciprocal. Research suggests that there are at least minor sex differences in brain anatomy in some species, and there is abundant evidence for other sex differences in CNS functioning. There is evidence, for example, of sexual dimorphism in the brains of rats and songbirds. Criminologist James Q. Wilson (1993) pointed out a variety of neurological differences between male and female humans - for example, that males are born less advanced neurologically; are four to six weeks less well developed; need more care; and are more prone to hyperactivity, autism, learning disorders, aggression, and so forth than females are. Although disproportionate male aggression is not well understood, Wilson pointed to a growing body of evidence implicating brain chemistry-hormones, enzymes (such as monoamine oxidase), and neurotransmitters such as serotonin. Breedlove (1994) 
summarized the status of research on sexual differentiation of the human nervous system. He was careful to point out that "except for the rather small difference in absolute brain weight, we do not know conclusively whether any of the sexual dimorphisms in the human brain are present at birth," and therefore, there is debate regarding whether such dimorphisms are innate or a result of differential environment (1994:400). Nevertheless, his review does point in the direction of a sex differentiated brain. For example, there is evidence that males have larger brains, though it still is not certain whether this is just because they have larger bodies overall (there being a slight correlation between body size and brain size (Breedlove 1994)) or because there is something different about male brain physiology. It is clear that males possess 25 percent more motoneurons in the spinal nucleus than females; these are related to innervation of perineal muscles and to aid ejaculation of semen, a function that females do not require. There are several indications that the female brain is less "lateralized" there is less hemispheric specialization for particular cognitive functions. For example, the discrepancy in performance when information is presented to one side of the brain is slightly greater in men than women, and physicians are able better to predict neuropsychological deficits in men compared to women when they know on which side of the brain a stroke lesion occurred (Breedlove 1994). The massa intermedia, a structure joining left and right thalamus, is not present in all humans but is more common in women than men ( 86 percent of women and 72 percent of men have the structure).

It is likely that more than anatomical differences, male and female brains differ in neurophysiological process. Simple genetic coding based on the Y chromosome is likely to be responsible for differences in hormonal production and infusion that initiate the differences in psychological processes characteristic of males and females. Increased androgen levels experienced by males at puberty are thought to be responsible for sex differences in spatial reasoning, and evidence from androgen insensitive genotypic males suggests they are similar to normal human females: patients had higher scores in verbal comprehension than perceptual organization (Breedlove 1994). Males who failed to produce gonadotropin and to experience puberty displayed a deficit in spatial ability compared to a group of normal males who had lost gonadotropin function after undergoing normal puberty. The same type of process is expected to operate on other psychological mechanisms that differ across the sexes.

Unfortunately, research on brain anatomy and neurophysiology is in its infancy, and neither has it established conclusively that innate differences in psychological structures exist between men and women. Nevertheless, the possibility or even the strong likelihood of brain differentiation is not in dispute (Blum 1997). Androgens, or male testicular hormones, are responsible for the masculinization of the body. As it happens, neurons, the building blocks of the brain and CNS, possess receptors that bind to those hormones (Breedlove 1994), suggesting that sexual differentiation of the CNS is possible.

\section{Summary}

Although the research on human brain neurophysiology, or neurochemistry, has not addressed the issue we raise directly, the research we have reviewed does suggest that (1) it is possible for sex differentiation to occur because neurons are responsive to androgens; (2) the brain does regulate emotions and humans probably have neurochemically orchestrated emotional reactions to social stimuli; and (3) there is some evidence that male and female brains have anatomical and neurophysiological differences. If we take into account social research that demonstrates sex differences in 
behavior and cognition in humans and nonhuman primates, we find a strong basis for proposing that human sociability is innate and sex differentiated.

\section{THE CHANGING NATURE OF SOCIAL CAPITAL}

Our earlier argument that social capital may be different things to different people now can be elaborated. It certainly is true that situational factors affect what constitutes "capital" for any given individual, and this creates a problem for conducting research on social capital where we seek to establish general laws of social behavior. If we take into account these situational factors and fail to ground our definition of social capital in motivating forces common across human beings, we end up with a limitless set of individual definitions of social capital, and our research cannot discover general laws of social behavior. We suggest that future research take human nature into account when choosing measures of social capital and measures of outcome.

An interesting problem emerges, however, because what constituted social capital in Africa in the Pleistocene Epoch is not going to be the same as what constitutes social capital today. For example, having a friend with a particular talent for making spears may have constituted social capital in the ancestral world, but not in the modern one. Further, the specialized social competencies and preferences that differentially evolved for men and women probably are not as adaptive as they once were. In modern America, for example, it is often in the best interest of a child for her or his mother to leave the home for the purpose of gainful employment. In this case, feeling deep separation anxiety when dropping a child off at the day care center, a physical response that probably was very fitness enhancing in the ancestral world, may work against the goal of reproductive success by preventing some women from pursuing careers (if such pursuit confers reproductive advantages on the child by increasing the likelihood the child will get adequate medical care, education, and other resources). Characteristics that make women good parents and close friends - characteristics such as becoming anxious when hearing about the problems of friends and acquaintances (Hayes 1991), heightened sensitivity (compared to men) to emotional facial cues (Geary 1998), strong bonding with children, and greater innate interest in and attraction to babies (Hess 1975) - may not be those that optimize promotions and pay raises in a modern male-dominated competitive business environment. A female manager may need a promotion or pay raise to afford medical expenses for her child (which will enhance RS) but may not have the natural inclination to compete with co-workers to seek attention for her achievements. But there is no sign that relationships high in social capital in the modern sense have become innately more pleasurable to women than relationships with sisters, close friends, and mothers, who probably have very little ability to promote women's material success.

It is likely that males, too, face an environment today where their reproductive success is not linked as closely with traits they acquired in the EEA. In modern middle-class society, for example, physical strength and aggression may lead to less resource acquisition for most men, not to more. Further, in a society with a norm of monogamy, males who refuse to devote themselves to one woman and to display paternal investment may find themselves childless due to advances in birth control and to the reduced likelihood that their sex partners will want to have their babies. Under these conditions, the reproductive success of men would be enhanced more by finding pleasure in the companionship of one woman than it would by 
finding pleasure sleeping around. Yet we suspect that most men still feel the tug of extramarital opportunities and that their most pleasurable feelings in relationships occur in relationships analogous to those that constituted social capital in the EEAtalking with male co-workers, meeting friends for a beer, playing touch football, finding new mates, and so forth. The landscape of psychological structures in our minds has not caught up to the selection pressures of modern society.

\section{CONCLUSION: WHY DO WE NEED A NEW DEFINITION OF SOCIAL CAPITAL?}

What is the utility of a new definition of social capital? The current incarnation of the concept of social capital is unsatisfying because it does not answer the ultimate question of "why" humans interact, the motivation for our behavior, our reasons for building capital, and for what capital is likely to be used. Further, the measures of social capital that have been based on its previous definitions have led to inconsistent empirical findings. Evolutionary psychology helps us connect social capital to human nature and thus provides for a more "grounded" conceptualization that will lead to a deeper understanding of sociability and social capital and to better research on both.

Another advantage of revising the definition is that while contemporary sociologists often see social capital as good for its own sake (because they believe it may be the glue that holds societies together), evolutionary psychology has no sentimental attachment to any particular kind of capital as an enduring "good." Social capital is a tool for the individual's selfish pursuit of reproductive success and is not accumulated for the benefit of the larger society. Social capital may have beneficial effects on societies, and for that reason social planners may desire to maintain the kinds of social relationships that seem to bind societies together. But individual choices of relationships will not be made, on the whole, because of this benefit unless, coincidentally, such relationships have a salient association with reproductive success.

We do not deny the appeal of focusing on the construct of social capital in the pursuit of understanding societal function. But because social capital inheres in individual human relationships, it is important to understand why humans established and maintained relationships in the first place and to find out more about the enduring aspects of relational dynamics. The recent lament that social capital is in decline demonstrates a very narrow view of human history. Americans today are upset to see that there are fewer and fewer intact two-parent "nuclear" families and that the social institutions we fondly recall from our youth (the welcome wagons, Boy Scouts, and bowling leagues) are on the wane. If we take a longer view, we soon see that such institutions were common only for a relatively short period in our very recent history. The nature of social ties varies a great deal across space and time, and research relying on any narrowly focused measures of social capital or positive life outcomes is likely to result in inconsistent findings. From our point of view, humans are drawn naturally to relationships that constitute social capital, and it is highly unlikely that social capital, in any enduring sense, will ever decline significantly. The shifts occur only because those relationships that constituted social capital in years past no longer constitute social capital today. Using the EP approach to social capital, we would not be inclined to cry about "bowling alone"; we would predict that, as society evolves, the nature of social relationships will as well. The only constant is that those relationships that people are most likely to treasure at any given point in time will be those associated with enhanced reproductive success. 
Although we have labored to make a strong case for the incorporation of EP and its concomitant genetic component in the conceptualization of social capital among sociologists, we acknowledge that the EP component of social capital is an addition to the current incarnation of the concept. While EP can help us understand some of the basic features of human sociability and therefore some of the dynamics of social capital (that humans will tend to seek out social relationships with powerful, talented, and/or attractive persons over ordinary persons - and why; that humans will use social capital for purposes consistent with survival, mating, and offspring promotion), its addition will not necessarily be useful in resolving all empirical questions such as the importance of weak ties in job success, cultural differences in network formation, and a host of related empirical questions that might be explained more parsimoniously with more proximate models of social capital.

\section{REFERENCES}

Barash, D. P. 1982. Sociobiology and Behavior, 2d. ed. New York: Elsevier.

Baron, S., J. Field, and T. Schuller, eds. 2001. Social Capital: Critical Perspectives. New York: Oxford University Press.

Beck, A. T. 1999. Prisoners of Hate: The Cognitive Basis of Anger, Hostility, and Violence. New York: Harper Collins.

Blum, D. 1997. Sex on the Brain: The Biological Differences Between Men and Women. New York: Penguin.

Bourdieu, P. 1983. "Forms of Capital.” Pp. 241-48 in Handbook of Theory and Research for the Sociology of Education, ed. J. G. Richardson. New York: Greenwood Press.

Bowlby, J. 1969. Attachment and Loss. Volume 1: Attachment. New York: Basic.

Breedlove, S. M. 1994. "Sexual Differentiation of the Human Nervous System." Annual Review of Psycho$\log y$ 45:389-418.

Burt, R. S. 1998. "The Gender of Social Capital.” Rationality and Society 10:5-46.

Buss, D. M. 1995. "Evolutionary Psychology: A New Paradigm for Psychological Science.” Psychological Inquiry 6:1-30.

-1999. Evolutionary Psychology: The New Science of the Mind. Boston, MA: Allyn and Bacon.

Campbell, K. E. 1988. "Gender Differences in Job-Related Networks." Work and Occupations 15:179-200.

Cartwright, J. 2000. Evolution and Human Behavior: Darwinian Perspectives on Human Nature. Cambridge, MA MIT Press.

Cohen, D., and L. Prusak. 2001. In Good Company: How Social Capital Makes Organizations Work. Cambridge, MA: Harvard Business School Press.

Coleman, J. S. 1988. "Social Capital in the Creation of Human Capital." American Journal of Sociology 94:S95-S120.

Cosmides, L. 1989. "The Logic of Social Exchange: Has Natural Selection Shaped How Humans Reason? Studies with the Wason Selection Task." Cognition 31:187-276.

Cosmides, L., and J. Tooby. 1992. "Cognitive Adaptations for Social Exchange.” Pp. 163-228 in The Adapted Mind: Evolutionary Psychology and the Generation of Culture, ed. J. H. Barkow, L. Cosmides, and J. Tooby. New York: Oxford University Press.

Daly, M., and M. Wilson. 1988. Homicide. New York: Aldine de Gruyter.

Davidson, R. J., and N. A. Fox. 1989. "Frontal Brain Asymmetry Predicts Infants' Response to Maternal Separation." Journal of Abnormal Psychology 98(2):127-31.

Deaux, K. 1976. The Behavior of Women and Men. Monterey, CA: Brooks/Cole Publishing.

de Haan, M., and C. A. Nelson. 1999. "Brain Activity Differentiates Face and Object Processing in SixMonth-Old Infants.” Developmental Psychology 32(4):1113-121.

Derryberry, D., and D. M. Tucker. 1992. "Neural Mechanisms of Emotion." Journal of Consulting and Clinical Psychology 60(3):329-38.

Edwards, B., M. W. Foley, and M. Diani, eds. 2001. Beyond Tocqueville: Civil Society and the Social Capital Debate in Comparative Perspective. Hanover, NH: University Press of New England.

Ekman, P. 1973. "Conclusion." Pp. 257-64 in Darwin and Facial Expression: A Century of Research in Review, ed. P. Ekman. New York: Academic Press. 
1992. "Facial Expressions of Emotion: New Findings, New Questions." Psychological Science 3(1):34-38.

Geary, D. C. 1998. Male, Female: The Evolution of Human Sex Differences. Washington, DC: American Psychological Association.

—. 1999. "Evolution and Developmental Sex Differences." Current Directions in Psychological Science 9(4):115-20.

. 2000. "Evolution and Proximate Expression of Human Paternal Investment." Psychological Bulletin 126(1):55-77.

. 2002. "Sexual Selection and Sex Differences in Social Cognition." Pp. 23-53 in Biology, Society, and Behavior: The Development of Sex Differences in Cognition, ed. A. McGillicuddy-De Lisi and R. De Lisi. Westport, CT: Ablex Pub.

Geary, D. C., and M. V. Flinn. 2002. "Sex Differences in Behavioral and Hormonal Response to Social Threat: Commentary on Taylor et al. (2000)." Psychological Review 109(4):747-50.

George, M S., T. Huggins, W. McDermut, P. I. Parekh, D. Rubinow, and R. M. Post. 1998. "Abnormal Facial Emotion Recognition in Depression: Serial Testing in an Ultra-Rapid-Cycling Patient.” Behavior Modification 22(2):192-204.

George, M. S., T. A. Ketter, P. I. Parekh, B. Horwitz, P. Herscovitch, and R. M. Post. 1995. "Brain Activity During Transient Sadness and Happiness in Healthy Women." American Journal of Psychiatry 152(3):341-51.

Geschwind, N. 1979. "Specializations of the Human Brain." Pp. 105-20 in The Workings of the Brain: Development, Memory, and Perception, ed. R.R. Llinás. New York: W.H. Freeman.

Halligan, P. W. 1998. "Inability to Recognize Disgust in Huntington's Disease." Lancet 351(9101):464.

Harper, L. V., and K. M. Sanders. 1978. "Sex Differences in Preschool Children's Social Interactions and Use of Space: An Evolutionary Perspective." Pp. 61-79 in Sex and Behavior: Status and Prospectus, ed. T.E. McGill and D. A. Dewsbury. New York: Plenum Press.

Hayes, L. L. 1991. "Sex Differences in Demands and Support of Social Networks." Unpublished dissertation. George Washington University.

Hess, E. H. 1975. The Tell-Tale Eye. New York: Van Nostrand Reinhold.

Hrdy, S. B. 1999. Mother Nature: A History of Mothers, Infants, and Natural Selection. New York: Pantheon.

Kampe, K. K. W., C. D. Frith, R. J. Dolan, and U. Frith. 2001. "Psychology: Reward Value of Attractiveness and Gaze." Nature 413(6856):589.

Kanazawa, S. 2001a. "De Gustibus Est Disputandum.” Social Forces 79:1131-63.

. 2001b. "Social Sciences Are Branches of Biology." Department of Sociology. Indiana University of Pennsylvania.

Kendrick, K. M., and B. A. Baldwin. 1987. "Cells in Temporal Cortex of Conscious Sheep Can Respond Preferentially to the Sight of Faces." Science 236(4800):448.

Kenrick, D. T., E. K. Sadalla, G. Groth, and M. R. Trost. 1990. "Evolution, Traits, and the Stages of Human Courtship: Qualifying the Parental Investment Model.” Journal of Personality 58:97-116.

Kinsey, A. C., W. B. Pomeroy, and C. E. Martin. 1948. Sexual Behavior in the Human Male. Philadelphia, PA: W.B. Saunders Company.

Kinsey, A. C., W. B. Pomeroy, C. E. Martin, and P. H. Gebhard. 1953. Sexual Behavior in the Human Female. Philadelphia, PA: W.B. Saunders Company.

Lane, R. D., E. M. Reinman, G. L. Ahern, G. E. Schwartz, and R. J. Davidson. 1997. "Neuroanatomical Correlates of Happiness, Sadness, and Disgust." American Journal of Psychiatry 154(7):926-33.

Laumann, E. O., and Y. Youm. 2001. "Sexual Expression in America." Pp. 109-47 in Sex, Love, and Health in America: Private Choices and Public Policies, ed. E. O. Laumann and R. T. Michael. Chicago, IL: University of Chicago Press.

Lawler, E. J., S. R. Thye, and J. Yoon. 2000. "Emotion and Group Cohesion in Productive Exchange." American Journal of Sociology 106:616-57.

Lawler, E. J., and J. Yoon. 1998. "Network Structure and Emotion in Exchange Relations." American Sociological Review 63:871-94.

LeDoux, J. 1996. The Emotional Brain: The Mysterious Underpinning of Emotional Life. New York: Simon and Schuster.

Lin, N. 2000. "Inequality in Social Capital." Contemporary Sociology 29:785-95.

. 2001. Social Capital. Cambridge: Cambridge University Press.

Lin, N., K. S. Cook, and R. S. Burt, eds. 2001. Social Capital: Theory and Research. New York: Aldine.

Luckow, A., A. Reifman, and D. N. McIntosh. 1998. "Gender Differences in Coping: A Meta-Analysis. Poster session presented at the 106th Annual Convention of the American Psychological Association, August 14-18, San Francisco, CA. 
Maccoby, E. 1998. The Two Sexes: Growing Up Apart, Coming Together. Cambridge, MA: Belknap Press of Harvard University Press.

Maccoby, E. E., and C. N. Jacklin. 1974. The Psychology of Sex Differences. Stanford, CA: Stanford University Press.

Mandal, M. K., H. S. Asthana, and S. Maitra. 1998. "Right Hemisphere Damage Impairs the Ability to Process Emotional Expressions of Unusual Faces.” Behavior Modification 22(2):167-76.

Marshall, J. E., and R. Heslin. 1975. "Boys and Girls Together: Sexual Composition and the Effect of Density and Group Size on Cohesiveness.” Journal of Personality and Social Psychology 31(5):952-61.

Maryanski, A., and J. H. Turner. 1992. The Social Cage: Human Nature and the Evolution of Society. Stanford, CA: Stanford University Press.

McNeal, Ralph B., Jr. 1999. "Parental Involvement as Social Capital: Differential Effectiveness on Science Achievement, Truancy, and Dropping Out.” Social Forces 78:117-44.

Mealey, L. 2000. Sex Differences: Development and Evolutionary Strategies. San Diego, CA: Academic Press.

Mitchell, G. 1981. Human Sex Differences: A Primatologist's Perspective. New York: Van Nostrand.

Moore, G. 1990. "Structural Determinants of Men's and Women's Personal Networks.” American Sociological Review 55:726-35.

Munch, A., J. M. McPherson, and L. Smith-Lovin. 1997. "Gender, Children, and Social Contact: The Effects of Childrearing for Men and Women." American Sociological Review 62(4):509-20.

Paxton, P. 1999. "Is Social Capital Declining in the United States?: A Multiple Indicator Assessment." American Journal of Sociology 105:88-27.

Portes, A. 2000. "The Two Meanings of Social Capital.” Sociological Forum 15:1-12.

Pratto, F., J. Sidanius, and L. M. Stallworth. 1993. "Sexual Selection and the Sexual and Ethnic Basis of Social Hierarchy.” Pp. 111-37 in Social Stratification and Socioeconomic Inequality, ed. L. Ellis. Westport, CT: Praeger.

Reiman, E. M., R. D. Lane, G. L. Ahern, G. E. Schwartz, R. J. Davidson, K. J. Friston, L.-S. Yun, and K. Chen. 1997. "Neuroanatomical Correlates of Externally and Internally Generated Human Emotion." American Journal of Psychiatry 154(7):918-25.

Renzulli, L. A., H. Aldrich, and J. Moody. 2000. "Family Matters: Gender, Networks, and Entrepreneurial Outcomes." Social Forces 79:523-46.

Ridley, M. 1993. The Red Queen: Sex and the Evolution of Human Nature. New York: Penguin.

Routtenberg, A. 1978. "The Reward System of the Brain." Pp. 75-87 in The Workings of the Brain: Development, Memory, and Perception ed. R.R. Llinás. New York: W.H. Freeman.

Schiff, M. 1992. "Social Capital, Labor Mobility, and Welfare: The Impact of Uniting States." Rationality and Society 4:157-75.

Schore, A. N. 2001. "The Effects of a Secure Attachment Relationship on Right Brain Development, Affect Regulation, and Infant Mental Health." Infant Mental Health Journal 22:7-66. Reprinted at www.trauma-pages.com.

Skarin, K., and B. E. Moely. 1976. "Altruistic Behavior: An Analysis of Age and Sex Differences." Child Development 47:1159-65.

Taylor, S. E., L. C. Klein, B. P. Lewis, T. L. Gruenwald, R. A. R. Gurung, and J. A. Updegraff. 2000. "Biobehavioral Responses to Stress in Females: Tend-and-Befriend, Not Fight-or-Flight." Psychological Review 107:411-29.

Tooby, J., and L. Cosmides. 1990. "The Past Explains the Present: Emotional Adaptations and the Structure of Ancestral Environments." Ethology and Sociobiology 11:375-424.

Trivers, R. L. 1972. "Parental Investment and Sexual Selection.” Pp. 136-79 in Sexual Selection and the Descent of Man, 1871-1971, ed. B. Campbell. Chicago, IL: Aldine.

Turner, J. H. 1987. "Toward a Sociological Theory of Motivation.” American Sociological Review 52:15-27. 2000. On the Origins of Human Emotions: A Sociological Inquiry into the Evolution of Human Affect. Stanford, CA: Stanford University Press.

Waite, L. J., and K. Joyner. 2001. "Emotional and Physical Satisfaction with Sex in Married, Cohabiting, and Dating Sexual Unions: Do Men and Women Differ? Pp. 239-69 in Sex, Love, and Health in America: Private Choices and Public Policies, ed. E. O. Laumann and R. T. Michael. Chicago, IL: University of Chicago Press.

Wellman, B., and S. Wortley. 1990. "Different Strokes from Different Folks: Community Ties and Social Support.” American Journal of Sociology 96(3):558-88.

Wilson, J. Q. 1993. “On Gender.” Public Interest 112:3-26.

Wright, R. 1994. The Moral Animal: The New Science of Evolutionary Psychology. New York: Vintage. 